Anja J.E. Dirkzwager, Peter G. van der Velden, Linda Grievink, \& C. Joris Yzermans.

Disaster-related posttraumatic stress disorder and physical health.

Psychosomatic Medicine, 69, 2007, nr. 5, p. 435-440.

\begin{tabular}{|c|c|}
\hline Postprint Version & 1.0 \\
\hline Journal website & http://www.psychosomaticmedicine.org/cgi/content/full/69/5/435 \\
\hline Pubmed link & $\begin{array}{l}\text { http://www.ncbi.nlm.nih.gov/sites/entrez?Db=pubmed\&Cmd=ShowDetailView } \\
\text { \&TermToSearch=17556645\&ordinalpos=2\&itool=EntrezSystem2.PEntrez.Pubm } \\
\text { ed.Pubmed ResultsPanel.Pubmed RVDocSum }\end{array}$ \\
\hline DOI & 10.1097/PSY.0b013e318052e20a \\
\hline
\end{tabular}

This is a NIVEL certified Post Print, more info at http://www.nivel.eu

\title{
Disaster-related posttraumatic stress disorder and physical health.
}

\author{
Anja J.E. DirkzWager ${ }^{1}$ (PhD), Peter G. VAN DER Velden² ${ }^{2}$ (PhD), Linda GrievinK ${ }^{3}$ (PhD), \& C. \\ JORIS YZERMANS ${ }^{1}$ (PHD) \\ ${ }^{1}$ Netherlands Institute for Health Services Research (NIVEL), Utrecht, the Netherlands. \\ ${ }^{2}$ Institute for Psychotrauma (IVP), Zaltbommel, the Netherlands. \\ ${ }^{3}$ Center for Environmental Health Research, National Institute for Public Health and the Environment \\ (RIVM), Bilthoven, the Netherlands.
}

Corresponding author: Anja J.E. Dirkzwager Netherlands Institute for Health Services Research P.O. Box 15683500 BN Utrecht the Netherlands Phone: + 31302729781 Fax: + 31302729729

E-mail: a.dirkzwager@nivel.nl

\begin{abstract}
Objective. Most studies on the relationship between posttraumatic stress disorder (PTSD) and physical health are cross-sectional and use self-reported physical health outcomes. The aim of the present study was to examine the relationship between PTSD and self-reported as well as physician-recorded physical health in a sample of survivors of a man-made disaster $(\mathrm{N}=896)$, using a longitudinal design that included pre-disaster health data as well.

Methods. A surveillance using the electronic medical records (EMRs) of survivors' family practitioners (FPs), one year pre-disaster till 4 years post-disaster, was combined with a survey, three weeks and 18 months post-disaster. Self-reported PTSD and self-reported physical health were assessed at 18 months post-disaster. FP-recorded physical health problems in the subsequent two years were classified according to the International Classification of Primary Care (ICPC). Multiple regression analyses were used to describe the relationships between PTSD and physical health.

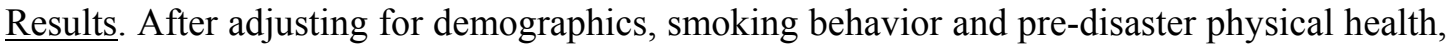
PTSD was significantly associated with FP-recorded vascular problems, musculoskeletal and dermatological problems, and with all self-reported physical health aspects. Prospectively, PTSD signaled an increased risk of new vascular problems ( $\mathrm{OR}=1.92 ; 1.04-3.55)$.

Conclusions. This study suggests an effect of PTSD in the development of vascular problems. The results imply that clinicians should be alert that disaster survivors with PTSD can suffer from comorbid medical problems as well.
\end{abstract}

$95 \% \mathrm{CI}=95 \%$ confidence interval $; \mathrm{BMI}=$ Body Mass Index; EMRs $=$ electronic medical records; $\mathrm{FP}=$ family practitioner; ICD-10 = International Classification of Diseases; ICPC $=$ International Classification of Primary Care; PTSD = posttraumatic stress disorder; OR = odds ratio; srs-PTSD= Self-Rating Scale for Posttraumatic Stress Disorder; DSM-IV $=$ Diagnostic and Statistical Manual of Mental Disorders, $4^{\text {th }}$ edition; SCL-90-R= Symptom Checklist-90 Revision; RAND-36= Short Form Health Survey-36. 
Anja J.E. Dirkzwager, Peter G. van der Velden, Linda Grievink, \& C. Joris Yzermans.

Disaster-related posttraumatic stress disorder and physical health.

Psychosomatic Medicine, 69, 2007, nr. 5, p. 435-440.

\section{INTRODUCTION}

On May 13, 2000, a fireworks depot exploded in a residential area in the city of Enschede in the

Netherlands. As a result, a large part of the neighborhood was destroyed, leaving 500 uninhabitable houses

and nearly 1,000 damaged ones. This resulted in the necessary relocation of approximately 1,200 residents. Twenty-three persons, including four fire fighters, were killed, and about 1,000 people were injured. After the disaster, a large scale monitoring study was started to investigate the health problems of the affected residents and rescue workers as well as the need for health care (1). The present study examined the relationship between posttraumatic stress disorder and physical health problems among the adult survivors of this disaster.

Disasters can have substantial and prolonged effects on both the psychological and physical health of survivors (2-4). Posttraumatic stress disorder (PTSD) is probably the most commonly studied psychological disorder in the aftermath of disasters and is characterized by having persistent intrusive memories about the traumatic event, by persistent avoidance of stimuli associated with the trauma, and by persistent increased arousal (5). In a comprehensive review, Galea and colleagues (2005) concluded that the prevalence of PTSD among directly exposed survivors of disasters is approximately $30-40 \%$ (2).

Psychological and physical health problems can be interrelated. It has been argued that PTSD may have an important effect on a person's physical health (6). Especially chronic PTSD may negatively affect physical health since it has been associated with adverse changes in neuroendocrine system functioning, such as altered cortisol, catecholamine and thyroid hormone levels (7-13). A large body of research has examined the relationship between stressful life events and physical health. Less is known, however, about the physical health effects associated with stress reactions following exposure to extreme stressors, such as disasters. Research on the relationship between PTSD and physical health has mainly used self-reported physical health outcomes (14), either assessed as self-reports of chronic medical disorders or physical symptoms, or more general ratings of health-related quality of life. These studies consistently demonstrated a significant and positive association between PTSD and self-reported physical health problems (15-18).

More objective assessments of health are physicians' diagnoses and laboratory data. However, until now few studies examined the relationship between PTSD and physical health using physician-diagnosed health problems as an outcome. Two studies among Vietnam war veterans and veterans of World War II and the Korea war did examine PTSD in relation to physician-diagnosed medical disorders (19-20). PTSD was associated with more physician-diagnosed medical disorders (19), and with an increased onset of physiciandiagnosed arterial, gastrointestinal, dermatological, and musculoskeletal disorders (20). Furthermore, patients with PTSD from medical centers of the Department of Veterans Affairs were more likely to have physician-diagnosed circulatory and musculoskeletal disorders, relative to patients without PTSD (21). The results of these studies were observed even after potential confounders (e.g. age, smoking behavior, alcohol use, BMI) were statistically controlled. Several other studies among male veterans that used objective measures (e.g. laboratory results, electrocardiograms) observed a relationship between PTSD and cardiovascular problems as well (22-24).

Longitudinal studies that examined the relationship between PTSD and physical health are rare, and information on the health status prior to the trauma is almost always unavailable. Additionally, only a few studies used objective health outcomes and these studies also had some limitations. First, although the study of Schnurr et al (20) was longitudinal, combat-related PTSD was not measured at study outset but approximately 20-30 years following combat, after many of the medical conditions had already occurred. Second, the studies examined primarily (male) military populations. The present study investigates the relationships between PTSD and physical health with a longitudinal design, including pre-disaster health data, in a sample of survivors of a man-made disaster. Data from two sources were combined: a survey and the electronic medical records (EMRs) of survivors' family practitioners (FPs). In this way we were able to examine whether survivors with PTSD 18 months post-disaster were at an increased risk of both selfreported and FP-recorded physical health problems. Because of the longitudinal design of the FP-data we were also able to examine whether PTSD was associated with the onset of new physical health problems. 
Anja J.E. Dirkzwager, Peter G. van der Velden, Linda Grievink, \& C. Joris Yzermans.

Disaster-related posttraumatic stress disorder and physical health.

Psychosomatic Medicine, 69, 2007, nr. 5, p. 435-440.

\section{METHOD}

\section{Subjects}

After the fireworks disaster the Ministry of Health, Welfare and Sports implemented two types of studies (1). Firstly, a longitudinal surveillance was started using the electronic medical records of the survivors' family practitioners (25). In the Netherlands, family practitioners have fixed patient lists and every person is registered with just one family practitioner, who must first be consulted if referral to secondary care is needed. In the surveillance, $73 \%$ of the FPs in the city of Enschede participated and together they covered $89 \%$ of all survivors. All data on health problems presented to the FP from one year pre-disaster till almost 4 years post-disaster were extracted from the electronic medical records in an anonymous format. Data collection procedures were in accordance with the privacy protection guidelines of the Dutch Data Protection Authority.

Secondly, a longitudinal survey was launched in which self-report questionnaires were filled in by affected residents (all 18 years or older) at three waves after the disaster (26-27). Three weeks post-disaster (wave 1) 1,567 residents filled in the questionnaire (estimated response rate $=35 \%$ ), and 1,116 of those participated 18 months following the disaster (wave 2; response rate $=71 \%$ ). Prior to the start of each survey the Medical Ethical Committee of the Netherlands Organization for Applied Scientific research (TNO, Zeist) approved the study protocol, and informed consents were obtained from all respondents.

For the present study, these two studies were combined, which resulted in 896 disaster survivors who participated in the survey at wave one and wave two (and provided complete data on the PTSD measure), and who were registered with the participating FPs as well. These 896 survivors were compared with the adult survivors (i.e. 18 years and older) of the surveillance who did not participate in the survey $(\mathrm{N}=7.488)$. The 896 survivors of the present study did not differ significantly from the other survivors with respect to age and insurance type. Compared to the other survivors, more survivors participating in both the survey and the surveillance were female $\left(50.0 \%\right.$ versus $\left.46.2 \% ; \chi^{2}=4.42, \mathrm{df}=1, \mathrm{p}<.05\right)$ and had to relocate due to the disaster $\left(16.3 \%\right.$ versus $\left.7.9 \% ; \chi^{2}=68.08, \mathrm{df}=1, \mathrm{p}<.0001\right)$.

\section{Instruments}

Family practitioners' data. The electronic medical records of the general practices were used. After each contact with a patient, FPs electronically register the presented health problems. All information on symptoms and diagnoses was classified according to the International Classification of Primary Care (ICPC), which is compatible with both the International Classification of Diseases (ICD-10) and the Diagnostic and Statistical Manual of Mental Disorders (DSM-IV) (28). For the present study, individual ICPC codes were combined in the following clusters of physical health problems: cardiovascular, musculoskeletal, gastrointestinal, respiratory, dermatological, headache and fatigue. These clusters were chosen based on literature linking traumatic exposure to poor health $(20,29)$, and because these clusters were prevalent enough for data analysis. The clusters included ICPC-codes for medical disorders as well as symptoms. When the cause of the presented complaint(s) can be determined, the FP will register the corresponding medical diagnosis (e.g. bronchitis). A FP will register symptoms when he or she cannot (yet) determine the cause of the complaints (e.g. coughing). Similar to the study of Schnurr et al. (2000), we wanted to examine the clusters cardiovascular and gastrointestinal into more detail, with a subdivision in hypertensive, ischemic, and arterial problems, and in lower and upper gastrointestinal problems. However, the numbers were only large enough to examine the sub-cluster arterial/vascular problems (e.g. peripheral vascular disease, atherosclerosis, varicose veins and edema). For each cluster it was calculated whether or not a person had presented one or more problems to the FP in a given period. Those who were registered in the general practice, but did not visit the FP received a score of zero. The present study investigated physical health problems presented to the FP in the two years after the PTSD assessment, and examined the prevalence as well as incidence of these physical health problems (the latter relating to problems present in the two years after the PTSD assessment while not present before).

In addition to the presented health problems, data on the following demographic characteristics were available: gender, age, immigrant status, and type of health insurance (i.e. private versus public). The latter variable was used as an indication for socioeconomic status because until 2006 people in the Netherlands had a private health insurance when their income was above a certain level.

\section{Self-report questionnaires}

The Self-Rating Scale for Post-Traumatic Stress Disorder (srs-PTSD) was used to assess disaster-related PTSD at 18 months after the disaster (30). The srs-PTSD contains 17 items corresponding to the DSM-IV 
Anja J.E. Dirkzwager, Peter G. van der Velden, Linda Grievink, \& C. Joris Yzermans.

Disaster-related posttraumatic stress disorder and physical health.

Psychosomatic Medicine, 69, 2007, nr. 5, p. 435-440. diagnostic criteria for PTSD, and assesses the severity of each item in the preceding four weeks. Nivger to
meet the criteria for a PTSD diagnosis, a person has to display at least 1 out of 5 re-experiencing symptoms, 3 out of 7 avoidance symptoms and 2 out of 5 hyperarousal symptoms. The srs-PTSD has good reliability and validity (30-31). Cronbach's alpha coefficient for this sample was .93.

At 18 months post-disaster, somatic complaints were assessed using the 'somatization' subscale (12 items) of the Dutch version of the Symptom Checklist-90-R (SCL-90-R; 32). A 5-point Likert scale (1= not at all, $5=$ very much) was used to measure the severity of these symptoms in the preceding week. Therefore, a higher score on the subscale represents a higher degree of somatic complaints. The validity and reliability of the Dutch SCL-90-R has proven to be satisfactory. Cronbach's alpha coefficient for the present population was .92 .

A Dutch translation of the Short Form Health Survey-36 (RAND-36) was used to measure the general health status 18 months post-disaster (33). Five subscales of the RAND-36, which most closely represented physical health problems, were included in the present study: role limitations in work or daily life due to physical health problems (4 items), bodily pain ( 2 items), physical functioning (10 items), general health (5 items), and vitality (4 items). A higher score on the RAND-36 scales represents a better functioning; for instance a high score on the Bodily Pain scale indicates the absence of pain. Cronbach's alpha coefficients for this sample ranged from .82 for the vitality scale to .92 for physical functioning.

At three weeks and 18 months post-disaster a question inquired about current smoking behavior (34). Those who indicated that they smoked on both times were classified as (persistent) smokers.

\section{Data analyses}

To examine the relationships between PTSD at 18 months post-disaster and physical health problems, multiple regression analyses were used. Multiple linear regression analyses were performed with the selfreported physical health problems (SCL-90 and RAND-36) as dependent variables. Multiple logistic regression analyses were used with FP-recorded physical health problems in the two years after the PTSD assessment as dependent variables. The independent variable was PTSD at 18 months post-disaster. Either beta coefficients or odds ratios with $95 \%$ confidence intervals (CI) will be presented, and the analyses were adjusted for age, gender, insurance type, immigrant status, and smoking behavior. Because the EMRs provided information on health problems presented to the FP prior to the disaster, we also adjusted for predisaster physical health problems in the analyses regarding the FP-recorded health problems. Multiple logistic regression analyses were also used to estimate the incidence of physical health problems (i.e. new onset in the two years following the PTSD assessment); this was only calculated for FP-rated health problems.

\section{RESULTS}

\section{Population characteristics}

On average the survivors were 44 years old at the time of the disaster $(\mathrm{SD}=14.42$; range $=17-83)$, half of them were male $(50 \%)$, and $71 \%$ had public health insurance. The minority of the survivors were single $(28 \%)$ and $16 \%$ had finished a high educational degree (i.e. university or vocational college). Sixteen percent $(\mathrm{N}=146)$ of the survivors were of foreign origin, of which 65 came from Turkey, 19 from Europe, and 62 from other parts of the world.

\section{PTSD}

Eighteen percent $(\mathrm{n}=160)$ of the survivors reported such a score on the Self-Rating Scale for PTSD that they met the criteria for PTSD 18 months post-disaster. In the period after the disaster, the FPs also diagnosed psychological health problems. The psychological problems most frequently recorded by the FPs were: acute and chronic stress reactions, sleeping disorder, anxious feelings, and depressive disorder. These four problems constituted $68 \%$ of all registered post-disaster psychological problems.

\section{PTSD and physical health}

Survivors with PTSD reported more physical health problems on the self-report questionnaires. Compared with survivors without PTSD, survivors with PTSD reported more bodily pain, a poor physical functioning, more limitations in their lives due to physical problems, and more somatic complaints (see Table 1). Furthermore, survivors with PTSD had less energy than non-PTSD survivors. 
Anja J.E. Dirkzwager, Peter G. van der Velden, Linda Grievink, \& C. Joris Yzermans.

Disaster-related posttraumatic stress disorder and physical health.

Psychosomatic Medicine, 69, 2007, nr. 5, p. 435-440.

[TABLE 1]

Compared with non-PTSD survivors, survivors with PTSD were more than twice as likely to be diagnosed by their FP with vascular problems, even when adjusted for personal characteristics, immigrant status, smoking behavior and pre-disaster vascular problems $(\mathrm{OR}=2.12$; see Table 2). Survivors with PTSD were also more often diagnosed with dermatological and musculoskeletal problems than survivors without PTSD.

Compared with those without PTSD, survivors with PTSD reported on average a greater number of physical health problems as well $(\mathrm{M}=4.88, \mathrm{SD}=4.29$ versus $\mathrm{M}=3.00, \mathrm{SD}=2.94 ; \mathrm{t}=-6.67, \mathrm{df}=894, \mathrm{p}<$ $.001)$.

\section{[TABLE 2]}

Additionally, we looked at the incidence of FP-rated physical health problems. Again, the survivors with PTSD at 18 months post-disaster were almost twice as likely to develop new vascular health problems in the two years after the PTSD assessment, after adjustment for demographics, smoking behavior, and predisaster physical health problems (see Table 2). For the other FP-recorded physical health problems no differences between survivors with and without PTSD were found with respect to new physical health problems.

\section{DISCUSSION}

Most prior work on the relationship between PTSD and physical health problems was cross- sectional in nature, used self-reported health outcomes, and concerned (male) military veterans. The present study enhances our knowledge by examining this relationship with a longitudinal design in a sample of disaster survivors. The results show that disaster survivors with PTSD at 18 months post-disaster were at an increased risk of FP-rated physical health problems in the subsequent two years. PTSD was significantly associated with FP-recorded vascular, musculoskeletal and dermatological problems. These relationships were observed even when demographic characteristics, smoking behavior and pre-disaster physical problems were statistically controlled. These findings were quite consistent with previous studies using physician's diagnoses, which also found significant associations between PTSD and cardiovascular, musculoskeletal and dermatological problems among military veterans and among patients exposed to a diversity of stressful life-events (19-21). Contrary to the study of Schnurr et al. (2000), we did not find a statistically significant association between PTSD and gastrointestinal problems. Several explanations for this difference are possible, such as variations in methods, design and populations, or variations with respect to the traumatic stressor. It is also possible that part of the veteran population had been exposed to toxicological agents, whereas no indications were found for the presence of relevant toxins in the aftermath of the disaster of the present study (1). Furthermore, Schnurr and colleagues only found a significant relationship for lower gastrointestinal problems; in the present study we were not able to make a subdivision in lower and upper gastrointestinal problems.

Because of the longitudinal design of the FP-data, we were also able to examine new physical health problems, which developed in the follow-up interval after the PTSD assessment and were not present before. A significant association was found for new vascular problems. In this case the PTSD preceded the onset of the vascular health problems, suggesting a potential effect of PTSD in the development of such problems. An alternative explanation for such a relationship may be that survivors with PTSD are more closely monitored by their FP and for instance have their blood pressure measured more frequently. In this case new physical problems may be discovered earlier among survivors with PTSD than among those without PTSD. To draw more firm conclusions about a potential causal effect of PTSD in the development of vascular problems, additional longitudinal studies are needed. Another prospective study, although based upon self-reported physical symptoms, found that PTSD at baseline was related to an increased likelihood of first onset of conversion symptoms (e.g. amnesia, loss of voice, fainting) and pain symptoms (e.g. pain in extremities, back pain, joint pain) during a five-year follow-up interval (35).

While PTSD was significantly associated with musculoskeletal and dermatological problems in the two years after the PTSD assessment, no significant relationship was found for new musculoskeletal and dermatological problems in this period. This suggests that these physical health problems had already been developed in the interval between the disaster and 18 months thereafter. Because we were not able to assess PTSD prior to 18 months post-disaster, we do not know when exactly the PTSD had developed, and 
Anja J.E. Dirkzwager, Peter G. van der Velden, Linda Grievink, \& C. Joris Yzermans.

Disaster-related posttraumatic stress disorder and physical health.

Psychosomatic Medicine, 69, 2007, nr. 5, p. 435-440. problems.

In addition to FP-recorded health problems, we observed that the survivors with PTSD evaluated their self-reported physical functioning and health-related quality of life as more negative than survivors without PTSD did. This finding was in line with previous work $(14,17,18,19,36)$. According to the norms of the SCL-90-R for the Dutch general population, the average score on the somatization scale was high (females) to very high (males) for the survivors with PTSD, whereas survivors without PTSD reported an average (females) to slightly above average (males) score (32). For the RAND-36 no Dutch norms are available. However, compared with the mean scores of a Dutch national sample, the survivors with PTSD scored 21 to 38 points lower on the five RAND-36 scales, and therefore reported lower levels of functioning (37). Survivors without PTSD, reported mean scores that differed between 0.2 and 8 points from this national sample.

An important question is how PTSD may influence physical health. Different mechanisms have been proposed to affect the association between PTSD and physical health, such as a direct effect through PTSD's associated neurobiology (e.g. a decreased immune function, alterations in hormone systems), as well as an indirect effect through cognitive and behavioral mechanisms such as coping, increased health risk behaviors (e.g. increased smoking or alcohol abuse), and a heightened symptom perception among people with psychological problems $(7,14)$. It is expected that multiple mechanisms will contribute in a complex, interacting way to the association between PTSD and physical health. Until now, however, the question how exactly PTSD affects physical health remains still unanswered. For instance, research on the biological correlates of PTSD, e.g. cortisol, epinephrine or dopamine, has not produced consistent results yet $(6,12)$. To further unravel this issue, more longitudinal and controlled studies on the relationships between PTSD and physical health are needed that use objective health indicators, such as physiciandiagnosed disorders, physical exams, or laboratory data.

Some methodological limitations of the present study need to be considered. A first concern is the representativeness of the study sample. The present study represents a relatively small group out of all survivors involved in the disaster, namely those who participated in the survey at both times and were enrolled in the surveillance as well. It is possible that selection has occurred, which may limit the generalizability of the results. A comparison of the respondents of the present study with survivors participating only in the FP-surveillance (this group represented $89 \%$ of all survivors) showed two significant differences, suggesting that women and severely affected survivors (i.e. those who had to relocate) may have been slightly overrepresented in the present study. Therefore, the results may be especially true for female and relocated survivors, and less generalisable to all survivors.

Secondly, we were not able to assess PTSD shortly after the disaster, PTSD was only assessed 18 months post-disaster. Therefore, no information was available with respect to the onset or duration of PTSD. Also the length of follow-up was relatively short. It has been argued that especially chronic PTSD may negatively affect physical health in the long run. Previous studies including physician-diagnosed problems examined veteran populations approximately 20-30 years after their combat experience and therefore had the opportunity to investigate these long-term relationships $(7,20)$. Possibly, with a longer timeframe we might have found additional significant relationships. Furthermore, individual physical health problems had to be combined into broad clusters of health problems because of low prevalence rates. This means that the clusters of health problems included both medical diagnoses and more subjective physical symptoms. Therefore, no conclusions on specific medical conditions as recorded by the FP can be drawn.

Finally, posttraumatic stress disorder was measured with a self-report questionnaire instead of a structured clinical interview, which is generally seen as the gold standard. However, sensitivity and specificity of the Self-Rating Scale for PTSD in relation to the structured clinical interview for PTSD were found to be good (30).

An important strength of the present study was the longitudinal study design including pre-disaster health data, which resulted in an additional confirmation of a relationship between PTSD and vascular problems, even when controlled for prior vascular problems. Another strength is the fact that information on physical health was obtained from two different kinds of sources: self-report measures and FP-registrations. Finally, the present study investigated survivors of a man-made disaster. To our knowledge the present study is the first study in the field of exposure to extreme stressors, which examined PTSD in relation to physical health in a non-military population using physician-recorded health outcomes. Thus, the present study adds 
Anja J.E. Dirkzwager, Peter G. van der Velden, Linda Grievink, \& C. Joris Yzermans.

Disaster-related posttraumatic stress disorder and physical health.

Psychosomatic Medicine, 69, 2007, nr. 5, p. 435-440.

important knowledge on the relationship between PTSD after exposure to extreme stressors and pipysice health.

The results imply that clinicians should be alert that disaster survivors with PTSD can suffer from comorbid medical problems as well. Especially in primary care, such survivors may initially present physical problems, while at the same time suffering from PTSD. If the relationship between PTSD and certain medical problems turns out to be causal, then early interventions aimed at preventing or reducing PTSD symptomatology might result in decreased health care costs for medical conditions.

\section{ACKNOWLEDGEMENT}

This study was funded by the Ministry of Health, Welfare and Sports in the Netherlands.

\section{TABLES}

TABLE 1. Relationships Between Disaster-Related PTSD (18 Months Postdisaster) and Self-Reported Physical Health Problems

\begin{tabular}{|c|c|c|c|c|c|}
\hline Self-Reported Health Problems ${ }^{a}$ & $\begin{array}{c}\text { PTSD } \\
\text { Mean } \pm \text { SD }\end{array}$ & $\begin{array}{c}\text { No PTSD } \\
\text { Mean } \pm \text { SD }\end{array}$ & $\beta^{b}$ & SE B & $95 \% \mathrm{Cl}$ \\
\hline Bodily pain (RAND-36) & $51.3 \pm 27.4$ & $78.1 \pm 23.2$ & -22.11 & 2.20 & -26.43 to -17.79 \\
\hline Physical functioning (RAND-36) & $62.5 \pm 28.8$ & $83.2 \pm 21.6$ & -15.63 & 1.99 & -19.56 to -11.71 \\
\hline Role limitations Physical (RAND-36) & $38.0 \pm 41.8$ & $74.3 \pm 36.5$ & -32.08 & 3.92 & -39.77 to -24.39 \\
\hline General health (RAND-36) & $38.0 \pm 20.4$ & $65.8 \pm 21.2$ & -22.50 & 1.90 & -26.23 to -18.78 \\
\hline Vitality (RAND-36) & $32.7 \pm 18.9$ & $60.2 \pm 19.2$ & -23.47 & 1.75 & -26.90 to -20.03 \\
\hline Somatic complaints (SCL-90-R) & $31.9 \pm 12.0$ & $17.3 \pm 6.1$ & 11.84 & 0.67 & 10.53 to 13.15 \\
\hline
\end{tabular}

PTSD = posttraumatic stress disorder; $\mathrm{SD}=$ standard deviation; $\mathrm{SE} \mathrm{B}=$ standard error of unstandardized $\beta$ coefficient; $\mathrm{CI}=$ confidence interval; RAND-36 = Short Form Health Survey-36; SCL-90-R = Symptom Checklist-90 Revision.

${ }^{a}$ A higher score on the RAND-36 represents better functioning, whereas a higher score on the SCL-90-R scale represents more somatic complaints.

${ }^{b}$ Unstandardized $\beta$ coefficients adjusted for age, gender, insurance type, immigrant status, and smoking behavior.

TABLE 2. Relationships Between Disaster-Related PTSD (18 Months Postdisaster) and Subsequent FP-Rated Physical Health Problems

\begin{tabular}{|c|c|c|c|c|c|c|c|c|c|c|c|c|}
\hline \multirow{3}{*}{ Physical Health } & \multicolumn{4}{|c|}{$\begin{array}{l}\text { Physical Health } \\
\text { Problems }\end{array}$} & \multirow{3}{*}{$\mathrm{OR}^{c}$} & \multirow{3}{*}{$95 \% \mathrm{Cl}$} & \multicolumn{4}{|c|}{$\begin{array}{c}\text { New Physical Health } \\
\text { Problems }{ }^{b}\end{array}$} & \multirow{3}{*}{$\mathrm{OR}^{c}$} & \multirow{3}{*}{$95 \% \mathrm{Cl}$} \\
\hline & \multicolumn{2}{|c|}{ PTSD } & \multicolumn{2}{|c|}{ No PTSD } & & & \multicolumn{2}{|c|}{ PTSD } & \multicolumn{2}{|c|}{ No PTSD } & & \\
\hline & $n$ & $\%$ & $n$ & $\%$ & & & $n$ & $\%$ & $n$ & $\%$ & & \\
\hline Cardiovascular-total & 51 & 31.9 & 197 & 26.9 & 1.23 & $0.78-1.94$ & 23 & 14.4 & 95 & 13.0 & 1.11 & $0.65-1.89$ \\
\hline Cardiovascular-vascular & 27 & 16.9 & 56 & 7.7 & 2.12 & $1.23-3.68$ & 20 & 12.5 & 45 & 6.2 & 1.92 & $1.04-3.55$ \\
\hline Respiratory & 74 & 46.3 & 224 & 30.6 & 1.46 & $0.99-2.16$ & 35 & 21.9 & 128 & 17.5 & 1.09 & $0.69-1.73$ \\
\hline Gastrointestinal & 69 & 43.1 & 191 & 26.1 & 1.44 & $0.96-2.17$ & 29 & 18.1 & 123 & 16.8 & 0.96 & $0.59-1.56$ \\
\hline Dermatological & 74 & 46.3 & 235 & 32.1 & 1.55 & $1.05-2.27$ & 39 & 24.4 & 149 & 20.4 & 1.15 & $0.74-1.78$ \\
\hline Musculoskeletal & 111 & 69.4 & 387 & 52.9 & 1.59 & $1.07-2.38$ & 27 & 16.9 & 127 & 17.4 & 0.94 & $0.57-1.53$ \\
\hline Headache & 31 & 19.4 & 58 & 7.9 & 1.60 & $0.93-2.77$ & 22 & 13.8 & 47 & 6.4 & 1.58 & $0.87-2.90$ \\
\hline Fatigue & 23 & 14.4 & 82 & 11.2 & 1.24 & $0.72-2.14$ & 17 & 10.6 & 68 & 9.3 & 1.07 & $0.58-1.96$ \\
\hline
\end{tabular}

PTSD = posttraumatic stress disorder; FP = family practitioner; $\mathrm{OR}=$ odds ratio; $\mathrm{CI}=$ confidence interval

${ }^{a}$ Health problems present in the 2 years after the PTSD assessment.

${ }^{b}$ Health problems present in the 2 years after the PTSD assessment, and not present previously.

${ }^{c}$ Adjusted for age, gender, insurance type, immigrant status, smoking behavior, and predisaster physical health problems.

\section{REFERENCES}

Roorda J, van Stiphout WA, Huijsman-Rubingh R. Post-disaster health effects: strategies for investigation and data-collection. Experiences from the Enschede firework disaster. J Epidemiol Community Health 2004;58: 982-7.

Galea S, Nandi A, Vlahov D. The epidemiology of posttraumatic stress disorder after disasters. Epidemiol Rev 2005;27:78-91.

Norris F, Friedman M, Watson PJ. 60.000 Victims speak, Part I \& II. Summary and implications of the disaster mental research. Psychiaty 2002;65:207-60.

Bland SH, O'Leary ES, Farinaro E, Jossa F, Trevisan M. Long-term psychological effects of natural disasters. Psychosom Med 1996;58:18-23. 
Anja J.E. Dirkzwager, Peter G. van der Velden, Linda Grievink, \& C. Joris Yzermans.

Disaster-related posttraumatic stress disorder and physical health.

Psychosomatic Medicine, 69, 2007, nr. 5, p. 435-440.

American Psychiatric Association. Diagnostic and statistical manual of mental disorders, $4^{\text {th }}$ ed. Washington
DC: American Psychiatric Association; 1994 .

Schnurr PP, Green BL. Trauma and health: physical health consequences of extreme stress. Washington

DC: American Psychological Association; 2004.

Boscarino JA. Posttraumatic stress disorder and physical illness. Results from clinical and epidemiologic

studies. Ann N Y Acad Sci 2004;1032:141-53.

Fukuda S, Morimoto K, Mure K, Maruyama S. Effect of the Hanshin-Awaji earthquake on post-traumatic stress, lifestyle changes, and cortisol levels of victims. Arch Environ Health 2000;55:121-25.

Maes M, Lin A, Bonaccorso S, van Hunsel F, van Gastel A, Delmeire L, Biondi M, Bosmans E, Kenis G, Scharpe S. Increased 24-hour urinary cortisol excretion in patients with post-traumatic stress disorder and patients with major depression, but not in patients with fibromyalgia. Acta Psychiatr Scand 1998;98:32835.

Mason JW, Wang S, Yehuda R, Lubin H, Johnson D, Bremner JD, Charney D, Southwick S. Marked lability in urinary cortisol levels in subgroups of combat veterans with posttraumatic stress disorder during an intensive exposure treatment program. Psychosom Med 2002;64:238-46.

Yehuda R, Kahana B, Binder-Brynes K, Southwick SM, Mason JW, Giller EL. Low urinary cortisol excretion in holocaust survivors with posttraumatic stress disorder. Am J Psychiatry 1995;152:982-6.

Young EA, Breslau N. Cortisol and catecholamines in posttraumatic stress disorder. Arch Gen Psychiatry 2004;61:394-401.

Wang S, Mason J. Elevations of serum T3 levels and that their association with symptoms in World War II veterans with combat-related posttraumatic stress disorder: replication of findings in Vietnam combat veterans. Psychosom Med 1999;61:131-8.

Schnurr PP, Janowski, MK. Physical health and post-traumatic stress disorder: review and synthesis. Semin Clin Neuropsychiatry 1999;4:295-304.

Boscarino JA. Diseases among men 20 years after exposure to severe stress: implications for clinical research and medical care. Psychosom Med 1997;59:605-14.

Engel CC, Liu X, McCarthy BD, Miller RF, Ursano R. Relationship of physical symptoms to posttraumatic stress disorder among veterans seeking care for Gulf War-related health concerns. Psychosom Med 2000;62:739-45.

Zatzick DF, Marmar CR, Weiss DS, Browner WS, Metzler TJ, Golding JM, Stewart A, Schlenger WE, Wells KB. Posttraumatic stress disorder and functioning and quality of life outcomes in a nationally representative sample of male Vietnam veterans. Am J Psychiatry 1997;154:1690-5.

Zayfert C, Dums AR, Ferguson RJ, Hegel MT. Health functioning impairments associated with posttraumatic stress disorder, anxiety disorders, and depression. J Nerv Ment Dis 2002;190:233-40.

Beckham JC, Moore SD, Feldman ME, Hertzberg MA, Kirby AC, Fairbank JA. Health status, somatization, and severity of posttraumatic stress disorder in Vietnam combat veterans with posttraumatic stress disorder. Am J Psychiatry 1998;155:1565-9.

Schnurr PP, Spiro A, Paris AH. Physician-diagnosed medical disorders in relation to PTSD symptoms in older male military veterans. Health Psychol 2000;19:91-7.

Ouimette P, Cronkite R, Henson BR, Prins A, Gima K, Moos RH. Posttraumatic stress disorder and health status among female and male medical patients. J Trauma Stress 2004;17:1-9.

Boscarino JA, Chang J. Electrocardiogram abnormalities among men with stress-related psychiatric disorders: implications for coronary heart disease and clinical research. Ann Behav Med 1999;21:227-34.

Falger PRJ, op den Velde W, Hovens JE, Schouten EG, de Groen JH, van Duijn, H.Current posttraumatic stress disorder and cardiovascular disease risk factors in Dutch Resistance veterans from World War II. Psychother Psychosom 1992;57:164-71.

Shalev A, Bleich A, Ursano RJ. Posttraumatic stress disorder: somatic comorbidity and effort tolerance. Psychosomatics 1990;31:197-203.

Yzermans CJ, Donker GA, Kerssens JJ, Dirkzwager AJE, Soeteman JH, ten Veen PMH. Health problems of victims before and after disaster: a longitudinal study in general practice. Int J Epidemiol 2005;34:8109.

Berg van den B, Grievink L, Stellato RK, Yzermans CJ, Lebret E. Symptoms and related functioning in a traumatized community. Arch Intern Med 2005;165:2402-07.

van Kamp I, van der Velden PG, Stellato RK, Roorda J, van Loon J, Kleber RJ, Gersons BBR, Lebret E. Physical and mental health shortly after a disaster: first results from the Enschede firework disaster study. Eur J Public Health 2005;16:252-258.

Lamberts H, Wood M. International Classification of Primary Care. Oxford: Oxford University Press; 1987. Friedman MJ, Schnurr PP. The relationship between PTSD, trauma, and physical health. In: Friedman MJ, Charney DS, Deutsch Y, editors. Neurobiological and clinical consequences of stress: From normal adaptation to PTSD. New York: Raven Press; 1995. p. 507-24. 
Anja J.E. Dirkzwager, Peter G. van der Velden, Linda Grievink, \& C. Joris Yzermans.

Disaster-related posttraumatic stress disorder and physical health.

Psychosomatic Medicine, 69, 2007, nr. 5, p. 435-440.

Carlier IVE, Lamberts RD, van Uchelen AJ, Gersons BPR (1998) Clinical utility of a brief diagnostictest for posttraumatic stress disorder. Psychosom Med 1998;60:42-7.

Brewin CR. Systematic review of screening instruments for adults at risk of PTSD. J Trauma Stress 2005;18:53-62.

Arrindell WA, Ettema JHM. SCL-90 handleiding [SCL-90 Manual]. Lisse, The Netherlands: Swets \& Zeitlinger; 1986.

van der Zee KI, Sanderman R. Het meten van de algemene gezondheidstoestand met de RAND-36. Een handleiding [Measuring general health with the RAND-36: a manual]. Groningen, The Netherlands: Noordelijk Centrum voor Gezondheidsvraagstukken; 1993.

Health Authority Netherlands. Standaard vraagstelling roken (Standardised questions for smoking). Utrecht, the Netherlands: GGD Nederland; 2003.

Andreski P, Chilcoat $\mathrm{H}$, Breslau B. Post-traumatic stress disorder and somatization symptoms: a prospective study. Psychiatry Res 1998;79:131-8.

Taft CT, Stern AS, King LA, King DW. Modelling physical health and functional health status: The role of combat exposure, posttraumatic stress disorder, and personal resource attributes. J Trauma Stress 1999;12:3-23.

Aaronson NK, Muller M, Cohen PDA, Essink-Bot M, Fekkes M, Sanderman R, Sprangers MAG, te Velde A, Verrips E. Translation, validation, and norming of the Dutch language version of the SF-36 health survey in community and chronic disease populations. J Clin Epidemiol 1998;51:1055-68. 